\title{
Spatial and Phenotypic Characterization of Vascular Remodeling in a Mouse Model of Asthma
}

\author{
Xinming Su ${ }^{a}$ d Namiko Taniuchi ${ }^{a}$ Enjing Jin ${ }^{a}$ Masakazu Fujiwara ${ }^{a}$ Lei Zhang ${ }^{a}$ \\ Mohammad Ghazizadeh $^{a}$ Hiroyuki Tashimo $^{b}$ Naomi Yamashita $^{c}$ Ken Ohta ${ }^{b}$ \\ Oichi Kawanamia \\ ${ }^{a}$ Department of Molecular Pathology, Institute of Development and Aging Sciences, Nippon Medical School, \\ Kawasaki, and ${ }^{\mathrm{b}}$ Department of Medicine, Teikyo University School of Medicine, and ${ }^{\mathrm{C}}$ Musashino University, Tokyo, \\ Japan; ${ }^{d}$ Institute of Respiratory Diseases, China Medical University, Shenyang, China
}

\section{Key Words}

Asthma $\cdot$ Lung $\cdot$ Mouse model $\cdot$ Phenotypes $\cdot$ Trachea $\cdot$ Vascular remodeling

\begin{abstract}
Asthma is a chronic inflammatory disease characterized by airway wall remodeling in which vascular remodeling is thought to be a main contributor. Vascular endothelial growth factor (VEGF) is known as a major regulator of angiogenesis and enhancer of vascular permeability. Here, we define the spatial nature of vascular remodeling and the role of VEGF and its receptors (Flt-1 and Flk-1) in the allergic response in mice $(A / J)$ susceptible to the development of allergen-induced airway hyperresponsiveness using morphometric and quantitative approaches. Increased vascularity, vasodilatation, and endothelial cell proliferation were found in the tracheal and bronchial walls in the early and late phases of asthma. Vascular changes were observed not only in small vessels but also in larger vessels. In contrast to normal control, lung tissue from the asthma model showed dual expression for CD31 and von Willebrand factor in the endothelial cells and $\alpha$-smooth muscle actin and desmin in the mural cells of the vessels, suggesting a phenotypic and functional transformation. The mRNA levels of VEGF isoforms, VEGF 164
\end{abstract}

and $\mathrm{VEGF}_{188}$, were significantly increased in the tracheal and lung tissue, respectively. In addition, the mRNA level of VEGF receptor Flk-1 was significantly increased in the trachea. These results establish the existence of vascular remodeling in the airways in a mouse model of allergic asthma and support a key role for the expression of unique VEGF isoform genes as mediators of structural changes.

Copyright $\odot 2008$ S. Karger AG, Basel

\section{Introduction}

Asthma is a complex disease characterized by airway inflammation with exaggerated $\mathrm{Th}_{2}$ cell, airway hyperresponsiveness and airway remodeling. Chronic inflammation leads to structural changes within the airways including an increase in the mass of smooth muscle (SM), the number of blood vessels (angiogenesis), and deposition of extracellular matrix proteins (collectively referred to as airway remodeling). In general, remodeling is an alteration in the size, mass, or number of tissue structural components that occurs during growth or in response to injury and/or inflammation. One of the important contributors to airway wall remodeling appears to be vascular remodeling. Vascular remodeling includes vas-

\section{KARGER}

Fax +4161306 1234

E-Mail karger@karger.ch

www.karger.com (c) 2008 S. Karger AG, Basel

1015-2008/08/0751-0042\$24.50/0

Accessible online at:

www.karger.com/pat
Prof. Oichi Kawanami, MD

Department of Molecular Pathology

Institute of Development and Aging Sciences, Nippon Medical School

1-396 Kosugi-cho, Nakahara-ku, Kawasaki 211-8533 (Japan)

Tel. +81 44733 1821, Fax +81 44733 1293, E-Mail kawanami@nms.ac.jp 
cular phenotype changes, increase in vessel number/unit area and increase in vessel activity, namely vasodilatation, leakage and cell migration to target tissue. All these processes lead to airway wall thickening and reduced air flow. It is therefore intriguing to clarify factors involved in airway vascular remodeling in asthma, which may result in vascular phenotype changes, increase in vessel numbers as well as activity suggested by vasodilatation, vessel leakage, and cellular margination and transmigration to target tissues. In addition, vascular alterations have been suggested to contribute to the airway hyperresponsiveness or obstruction.

In asthma, an increase in vessel size, vessel number, and vascular surface area, and the overexpression of VEGF (referred to as VEGF-A) has been suggested. Mouse VEGF-A mRNA exists in at least five isoforms, $\mathrm{VEGF}_{120}$, $\mathrm{VEGF}_{144}, \mathrm{VEGF}_{164}, \mathrm{VEGF}_{188}$ and $\mathrm{VEGF}_{205}$, produced by alternative splicing of a primary transcript from a single VEGF gene [1]. The different isoforms have been reported to exhibit distinct biologic activities [2] and expression levels in different tissues [1] or the same tissue at various stages from embryo to adult [3]. However, the mechanisms regulating each VEGF isoform remain largely unknown. The various VEGF isoforms share two main tyrosine kinase receptors, Flt-1 (VEGFR-1) and KDR/Flk-1 (VEGFR-2) [4], but fulfill somewhat different functions in vivo as revealed by targeted gene disruption experiments $[5,6]$.

The development of a mouse model of asthma has given new insights into mechanisms of vascular responses. In the present study, our objective was to assess spatial and phenotypic changes in vascular remodeling and the role of VEGF and its receptors Flt- 1 and Flk-1 in an ovalbumin (OVA)-induced mouse model of allergic asthma. This animal model closely resembles human allergic asthma physiologically, serologically, immunologically, pathologically, and molecular biologically $[7,8]$.

\section{Materials and Methods}

\section{Animals and Sensitization}

Male A/J mice, a strain known to be genetically predisposed to airway hyper-responsiveness to acetylcholine [7], purchased from SLC (Shizuoka, Japan), were initially immunized (IgE) by 4 times intraperitoneal injection of $10 \mu \mathrm{g}$ OVA $+2 \mathrm{mg}$ aluminum hydroxide gel (on weeks $0,4,5$, and 7). Subsequently, $20 \mathrm{mg} / \mathrm{ml}$ OVA inhalations were done for 20 min everyday for 1 week (considered early phase of asthma, 15-16 weeks old, body weight 17.4$24.2 \mathrm{~g}$ ) or 5 weeks (late phase of asthma, 19-20 weeks old, body weight 26.3-29.8 g), using the ultrasonic nebulizer $3 \mathrm{ml} / \mathrm{min}$ (Omron, Tokyo, Japan). Mean particle diameter was $3.0 \mu \mathrm{m}$. Un- treated A/J mice were used as control subjects (14-17 weeks old, body weight 25.9-30.0 g). Care and use of the animals followed the guidelines 'Principles of Laboratory Animal Care' formulated by the National Society for Medical Research. These mice were specified as pathogen free.

Intraperitoneal administration of OVA + alum leads to allergen-specific $\mathrm{Th}_{2}$ immunity which was necessary for respiratorytract antigen challenge to efficiently induce allergic asthma. A previous report has demonstrated that this mouse model showed the following characteristics: (i) induces airway hyperresponsiveness to acetylcholine, (ii) increased serum total IgE and OVA-specific IgE, (iii) analysis of bronchoalveolar lavage fluid showed both increased number of total cells and the fraction of eosinophils, (iv) histologically, airway ciliated cells were replaced by mucus-secreting cells and many inflammatory cells accumulated in the subepithelial area by hematoxylin and eosin (HE) and periodic acid-Schiff staining, and (v) induces inflammatory cytokine mRNA expression, e.g. IL-4 and IL-5, in the lung [8]. Collectively, they mimicked human asthma physiologically, serologically, immunologically, pathologically and molecular biologically.

\section{Vascular Perfusions}

Within $24 \mathrm{~h}$ after the last aerosol OVA inhalation, animals were anesthetized with Nembutal (pentobarbital sodium, $30 \mathrm{mg}$ / $\mathrm{kg}$ i.p.) and dissected. Under anesthesia, the diaphragm of mice was opened keeping the physiological blood circulation in thoracic cages as long as possible in order to avoid damage to the chest cavity. A catheter with a sharp point $(0.9 \mathrm{~mm}$ inside diameter) was inserted into the ascending aorta from the apex of the heart and clamped. FITC-dextran was infused or instantly $24 \mathrm{ml}$ of $0.5 \%$ heparin sodium was perfused at $5 \mathrm{ml} / \mathrm{min}$, followed by $20 \mathrm{ml}$ of $4 \%$ paraformaldehyde in $0.1 \mathrm{M}$ phosphate-buffered saline (PBS), $\mathrm{pH} 7.4$, at the same speed for fixing. After cutting a midline incision in the sternum, the trachea was removed and opened outward at the site of the membranous part of the trachea. The examination site was the 3rd cartilage from the carina of the trachea to the 2nd cartilage site of the left bronchus. Remaining bilateral bronchi and lung tissue were embedded in OCT compound and frozen in liquid nitrogen for $\mathrm{HE}$ and immunofluorescence staining.

\section{Staining of Whole Tracheal Microvasculature}

After the trachea was removed and opened, we treated the whole flattened tracheal tissue with $0.1 \%$ Triton X-100 for osmosis of antibodies. Briefly, tracheal tissue was placed in a laboratory dish and treated in a floating fashion with $0.1 \%$ Triton X-100 (Sigma, St. Louis, Mo., USA) in PBS for $1 \mathrm{~h}$, followed by rinsing with PBS for $5 \mathrm{~min}$. Then the tissue was similarly treated overnight at $4{ }^{\circ} \mathrm{C}$ with primary antibodies; (i) rat anti-mouse CD31 (platelet endothelial cell adhesion molecule, PECAM-1) monoclonal antibody diluted 1:50 with $1 \%$ bovine serum albumin in PBS (BD Pharmingen, Franklin Lakes, N.J., USA), and (ii) rabbit anti-von Willebrand factor (vWF) polyclonal antibody (diluted 1:400; DAKO, Copenhagen, Denmark). Next, the tissues were washed with PBS 3 times each for $5 \mathrm{~min}, 0.1 \%$ Triton X-100 in PBS for $1 \mathrm{~h}$, PBS once for $5 \mathrm{~min}$, and finally incubated for $2 \mathrm{~h}$ at room temperature in the secondary antibodies: (i) Alexa Fluor 594 (Alexa594)-labeled goat anti-rat IgG (Molecular Probes, Eugene, Oreg., USA), and (ii) FITC-labeled goat anti-rabbit IgG (Vector Laboratories, Burlingame, Calif., USA) diluted 1:100, respectively, followed by rinsing with PBS 3 times, each for $10 \mathrm{~min}$. Fluores- 
cent-stained tracheas were mounted in $10 \%$ glycerin in PBS and examined with a laser scanning confocal microscope (TC-SP; Leica, Heidelberg, Germany).

Staining of Lung Tissue

Peripheral lung tissue was fixed by vascular perfusion with $4 \%$ paraformaldehyde in PBS. Following removal of the trachea, the remaining bilateral lung tissue was excised and soaked in $4 \%$ paraformaldehyde/PBS for $1 \mathrm{~h}$. The tissues were treated with 15, 20 , and $30 \%$ sucrose each for $4 \mathrm{~h}$, respectively, then embedded in OCT compound (Chiba Medical, Chiba, Japan) and frozen in liquid nitrogen. Frozen blocks were sectioned at 4-6 $\mu \mathrm{m}$ using a cryostat microtome (Clinicut; Shiraimatu, Shiga, Japan), stained for CD31/vWF, CD31/desmin and CD31/ $\alpha$-SM actin ( $\alpha$ SMA) using a double immunofluorescence method and observed by a laser scanning confocal microscope (TC-SP, Leica). Briefly, cryostat sections were incubated in $10 \%$ normal goat serum (Sigma) for 20 min at room temperature to block nonspecific antibody binding. Next, the sections were incubated overnight at $4^{\circ} \mathrm{C}$ in humidified chambers in combinations of two diluted primary antibodies. Phenotypic characterization of endothelial cells was performed with the following antibodies: rat anti-mouse CD31 monoclonal antibody (diluted 1:50 with 1\% bovine serum albumin in PBS; BD Pharmingen), rabbit anti-vWF polyclonal antibody (diluted 1:400; DAKO), rabbit anti-desmin polyclonal antibody (diluted 1:200; DAKO Cytomation, Carpinteria, Calif., USA), and FITCconjugated mouse anti- $\alpha$ SMA monoclonal antibody (diluted 1:250, Sigma). After several rinses with PBS, specimens were incubated for $2 \mathrm{~h}$ at room temperature with fluorescent secondary antibodies: (i) Alexa594-labeled goat anti-rat IgG (Molecular Probes), and (ii) FITC-labeled goat anti-rabbit IgG (Vector Laboratories) diluted 1:100 followed by several rinses in PBS. Finally, specimens were mounted in 10\% glycerin in PBS.

Sections were stained for CD31/ $\alpha$ SMA/TOTO- 3 by the triple immunofluorescence method. After incubation with the primary and secondary antibodies (same as above), sections were incubated for $0.5 \mathrm{~h}$ at room temperature with TOTO-3 for nuclear staining. Finally, after several rinses with PBS, the sections were mounted in $10 \%$ glycerin in PBS.

All immunofluorescence staining sections were examined by a laser scanning confocal microscope. OCT compound sections were also evaluated by routine HE staining and examined with a light microscope (Eclipse E800M light microscope; Nikon, Tokyo, Japan) equipped with Nomarski differential interference contrast technique. We observed and saved immunofluorescence and $\mathrm{HE}$ images from the same vessels. Each group of triple immunofluorescence images were merged together for presentations.

\section{Vessel Measurement and Cell Count}

Measurements of vessel perimeter and diameter in each group were performed using the NIH ImageJ, and 150 vessels were measured in each group ( 30 vessels per mouse). We divided the vessels into three groups according to the diameter (large vessels: diameter $>100 \mu \mathrm{m}$; middle vessels: diameter $40-100 \mu \mathrm{m}$, and small vessels: diameter 10-40 $\mu \mathrm{m})$. We counted the number of endothelial cells and mural cells and compared them in normal and asthma models among different groups. To avoid errors resulting from sectioning directions, we selected vessels that were sectioned with respect to the long axis of the vessel.

\section{RT-PCR Analysis}

Bronchial and lung tissue of $\mathrm{A} / \mathrm{J}$ asthma (5 mice) and control mice (5 mice) was used for reverse transcription-polymerase chain reaction (RT-PCR) to assess the expression of mRNA isoforms of VEGF and its receptors. For RT-PCR, tissue was isolated directly after anesthesia and frozen in liquid nitrogen. Total RNA was extracted using the RNeasy Mini Kit (Qiagen, Hilden, Germany) with DNase treatment. cDNA was synthesized from total RNA with oligo(dT) as a primer using SuperScript II RNase HReverse Transcriptase (Gibco BRL, Rockville, Md., USA) at $37^{\circ} \mathrm{C}$ for 1.5 h. PCR was carried out for VEGF and VEGF receptors (Flt-1 and Flk-1) using an 1- $\mu$ l aliquot of cDNA mixed from 5 mice.

We devised an RT-PCR strategy to analyze different murine VEGF isoforms using one common forward and reverse primer. Since all VEGF isoforms share the same exons (1-5 and 8), the common forward and reverse primers were able to amplify all VEGF isoforms. The following primers spanned these variable splice regions of VEGF mRNA: forward: TAC ATC TTC AAG CCG TCC TGT, and reverse: TCC TCT TCC TTC ATG TCA GGC. Using the described primers, the expected PCR products for each VEGF variant would be: $382,454,514,586$ and $637 \mathrm{bp}$ for the VEGF isoforms of 120, 144, 164, 188 and 205 amino acids, respectively. The following primers of VEGF receptor (Flt-1 and Flk-1) mRNA were used: Flt-1 forward: GTC AAT GAG CCA TCA AAA GGA; Flt-1 reverse: TGT TCT CAT CCG TTT CTC TGG, and Flk-1 forward: ATA TCC CAT TGG AGG AAC CA, and Flk-1 reverse: TCA ACA CA CAA AGC ATT GCC. Using the described primers, the expected PCR products for VEGF Flt-1 and Flk-1 would be 598 and $690 \mathrm{bp}$, respectively. The PCR of VEGF was performed at $94^{\circ} \mathrm{C}$ for $30 \mathrm{~s}, 57^{\circ} \mathrm{C}$ for $30 \mathrm{~s}$, and $72^{\circ} \mathrm{C}$ for $1 \mathrm{~min}$. After 30 cycles of amplification, cDNA products were electrophoresed on $2 \%$ agarose gels and visualized with SYBR green I (Molecular Probes), and band images were captured using Molecular Imager FX, and normalized to or against glyceraldehyde-3-phosphate dehydrogenase (GAPDH) signal intensity. GAPDH was used as an internal control and detected at uniform levels. The analyses were done using NIH Image Software. The PCR of VEGF Flt- 1 and Flk- 1 was performed at $94^{\circ} \mathrm{C}$ for $30 \mathrm{~s}, 56^{\circ} \mathrm{C}$ for $45 \mathrm{~s}$, and $72^{\circ} \mathrm{C}$ for $1.5 \mathrm{~min}$ for 30 cycles.

\section{Statistical Analysis}

Experimental group sizes consisted of 5 mice per group. All values were recorded as means \pm SEM (SE). The significance of differences between means was assessed by the t test for comparisons, with statistical significance set as $\mathrm{p}<0.05$.

\section{Results}

\section{Histological Features of Normal Lung Tissue, and during Early and Late Phases of Asthma}

The representative micrographs from $\mathrm{HE}$-stained sections of control lung and early- and late-phase asthma in $\mathrm{A} / \mathrm{J}$ mouse lung focusing on the bronchial structures are depicted in figure 1. Compared to the controls (fig. 1a), inflammatory cell infiltration, prominent SM cells 

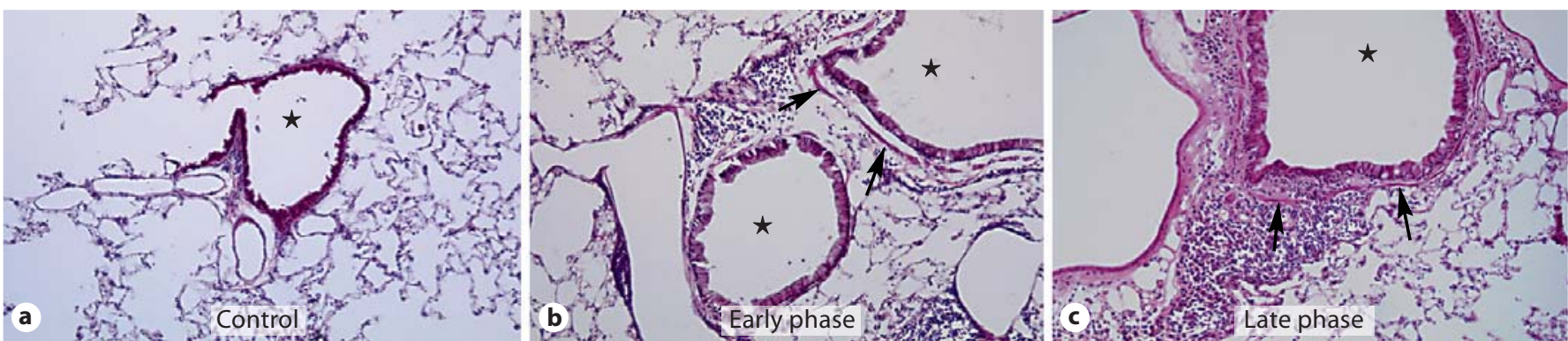

Fig. 1. Representative micrographs from HE-stained sections of control, early-phase and late-phase asthmatic $\mathrm{A} / \mathrm{J}$ mouse lung showing bronchial structures (asterisks). Compared to the control (a), inflammatory cell infiltration, prominent SMCs (arrows), collagen deposits, edema, and thickening of the bronchial wall are seen in the early (b) and late phase (c) of asthma. Also, bronchial epithelial cells demonstrate metaplastic change into mucin-producing type $(\mathbf{b}, \mathbf{c})$.
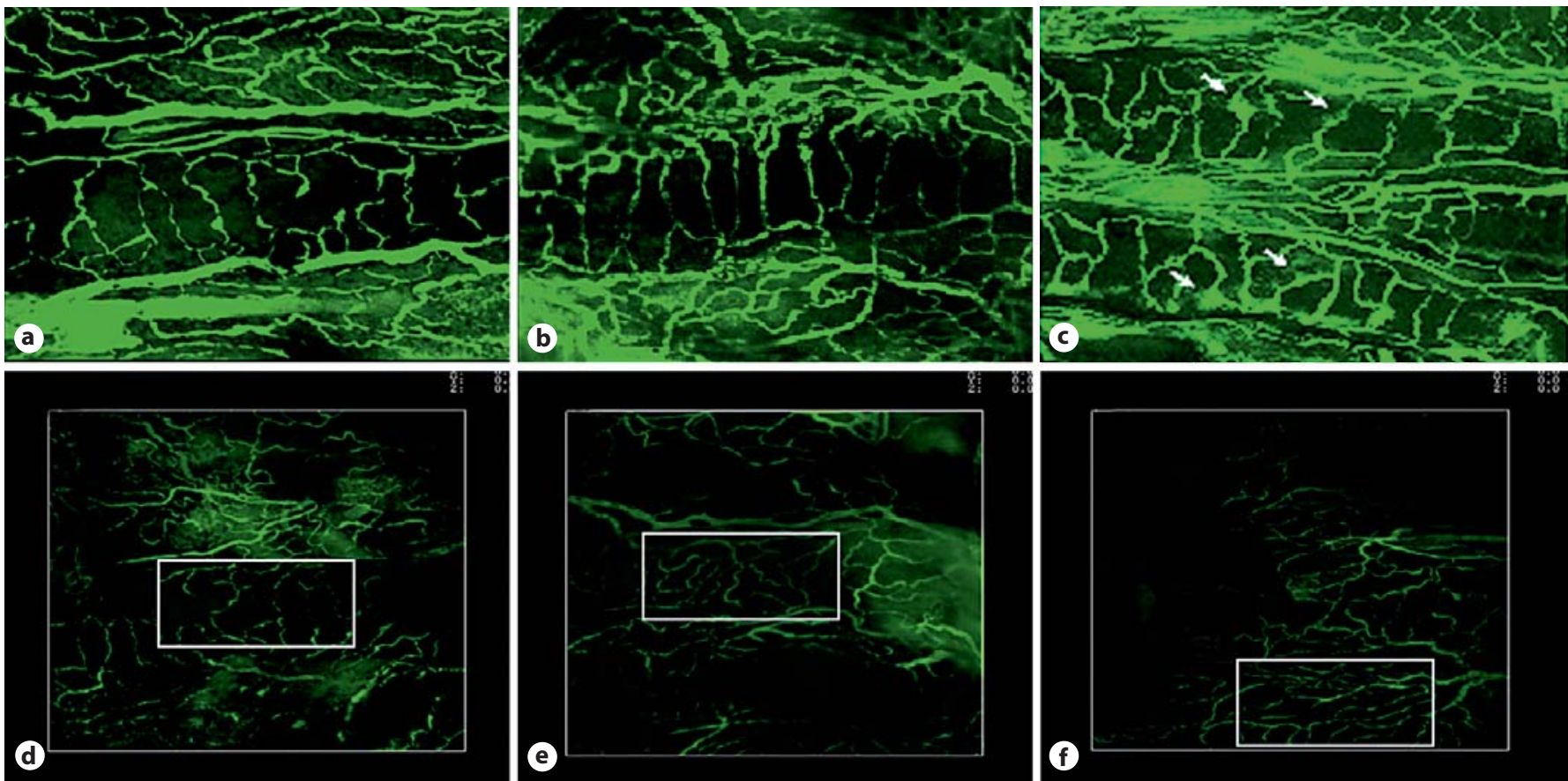

Fig. 2. Enhanced vascularity and vasodilatation were observed in the tracheal $(\mathbf{a}-\mathbf{c})$ and bronchial walls $(\mathbf{d}-\mathbf{f})$ in the early $(\mathbf{b}, \mathbf{e})$ and late phases (c, f) compared to the control (a, d); twisting of the capillaries, dilatation and leakage (arrows) were observed in the tracheal wall vessels in the late phase, too (c). Vascularity in murine tracheal and bronchial wall vessels was detected by morphometric measurements of area densities (\% of total tissue area), showing a significantly enhanced vascularity in the tracheal walls in the late phase, and in the bronchial wall, both in the early and late phase of asthma $(\mathbf{g}) .{ }^{*} \mathrm{p}<0.05$.

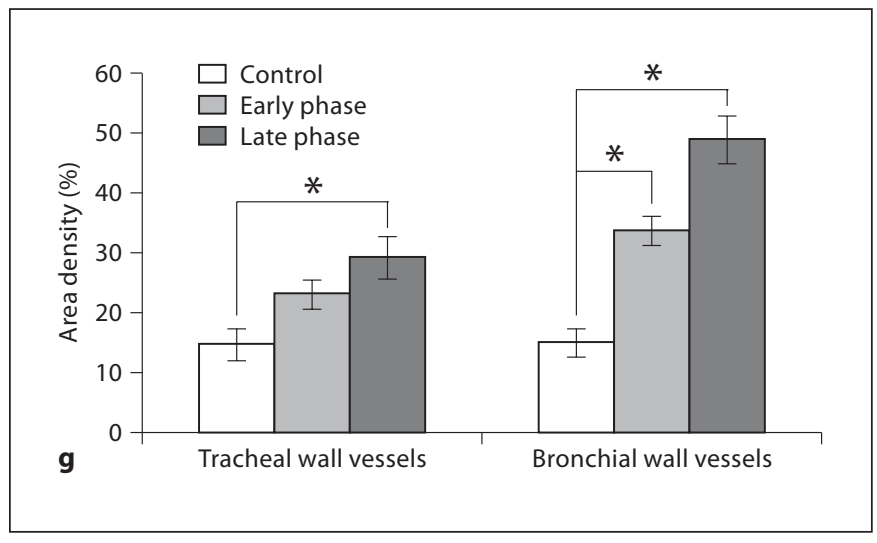


(SMCs), collagen deposits, as well as edema leading to the thickening of the bronchial wall are noticed in the early (fig. 1b) and late (fig. 1c) phase of asthma. In addition, bronchial epithelial cells show a metaplastic change into the mucin-producing type (fig. $1 \mathrm{~b}, \mathrm{c}$ ). These findings confirm that the A/J mouse model of asthma presents the typical histopathological features of human asthma.

\section{Visualization of Tracheal and Bronchial Wall Vessels}

To assess changes in the lung vascular network of the $\mathrm{A} / \mathrm{J}$ mouse asthma model, we attempted to visualize the complex network of microvessels in tracheobronchial trees and lung parenchyma by injection of FITC-dextran via the bronchial artery as previously reported [9]. In the membranous part of the trachea, capillaries were arranged in parallel along the longitudinal axis of the trachea figure $2 \mathrm{a}$. They occasionally anastomosed with adjacent vascular branches. In a thin layer covering cartilage matrices (approximately $50 \mu \mathrm{m}$ thick), capillaries showed a rather parallel array along the longitudinal axis as found in the membranous part, and they converged into a polygonal capillary meshwork in the intercartilage soft part. These capillaries were connected with venules running exclusively in intercartilage soft tissue of the trachea. In the bronchial airways (fig. 2b), capillaries were arranged in a ring-like pattern with a relatively constant distance (about $20 \mu \mathrm{m}$ ) between them. Each capillary ring rarely made anastomoses, while the bronchial arteries ran obliquely along the longitudinal axis of the bronchial tube. Peribronchial soft tissue was scarce in the mouse lung and contained only a few microvessels.

By FITC-dextran infusion, enhanced vascularity and vasodilatation were observed in the tracheal (fig. $2 \mathrm{a}-\mathrm{c}$ ) and bronchial (fig. 2d-f) walls in the early (fig. 2b, e) and late (fig. 2c, f) phases as compared to the controls (fig. 2a, d). In addition, twisting of the capillaries, dilatation and leakage (arrows) were observed in the tracheal wall vessels in the late phase (fig. 2c).

Vascularity in tracheal and bronchial wall vessels was detected by morphometric measurements of area densities (\% of total tissue area). The result showed a significantly enhanced vascularity in the late phase in the tracheal and bronchial wall, and in the early phase in the bronchial wall of asthmatic mouse (fig. $2 \mathrm{~g}$ ).

\section{Immunofluorescence Phenotypes of Endothelial and Mural Cells}

Whole tracheal tissue was stained for CD31 and coagulation factor, vWF, and the peripheral lung tissues were stained for CD31/vWF, CD31/desmin and CD31/ $\alpha$ SMA by a dual immunofluorescence method. Phenotypic characteristics of endothelial cells and remodeling of blood vessels were observed in tissue sections from tracheobronchial walls in the $\mathrm{A} / \mathrm{J}$ mouse asthma model.

\section{Phenotypes of Endothelial Cells in Mouse Trachea}

CD31/vWF Expression

In dual immunofluorescence staining, CD31 was labeled with Alexa594 (red) and vWF with FITC (green). CD31 is also known as PECAM-1 that mediates cell-tocell adhesion and is constitutively expressed by endothelial cell membrane.

Figure 3 demonstrates that the vascular network (all types of blood vessels) expressed CD31. In contrast, comparatively larger vessels located in the intercartilage soft part (morphologically looking like venules) expressed both CD31 and vWF as illustrated by yellow color (fig. 3a). In a thin layer covering cartilage matrices (approximately $50 \mu \mathrm{m}$ thick), capillaries showed a rather parallel array along the longitudinal axis and converged into a polygonal capillary meshwork in the intercartilage soft part (fig. 3d). These capillaries were connected with venules running in intercartilage soft tissue of the trachea corresponding to vWF-positive vessels. In the healthy control mouse, endothelial cells of venules located in the intercartilage showed vWF positivity and any other capillaries in the trachea were negative for vWF. At higher magnifications, the microvessels located in the border zone between cartilage and intercartilage were characterized by a mosaic-like mixed distribution pattern of CD31 and vWF expression in endothelial cells (fig. 3d).

In contrast, the intercartilage capillaries in the asthma model showed irregularity, enlargement, tortuousness, having knob or boss, and sometimes interruptions in the CD31 expressional pattern (red), reflecting angiogenesis or vascular remodeling (fig. $3 \mathrm{~b}, \mathrm{e}$ ). Concerning the characteristics of the endothelial cell phenotype, in contrast to normal control, we observed less and spotted CD31 expression in venules located in the intercartilage soft part in the asthma model. The positive expression for vWF (green) appeared in the endothelial cells located in the cartilage and occasionally in the border zone between cartilage and intercartilage (fig. $3 b, c, e, f$ ).

\section{Phenotypes of Endothelial Cells in Mouse Lung CD31/vWF Expression}

In dual immunofluorescence staining, CD31 and vWF were labeled by Alexa594 (red) and FITC (green), respectively. In the normal mouse lung, the cytoplasm of 

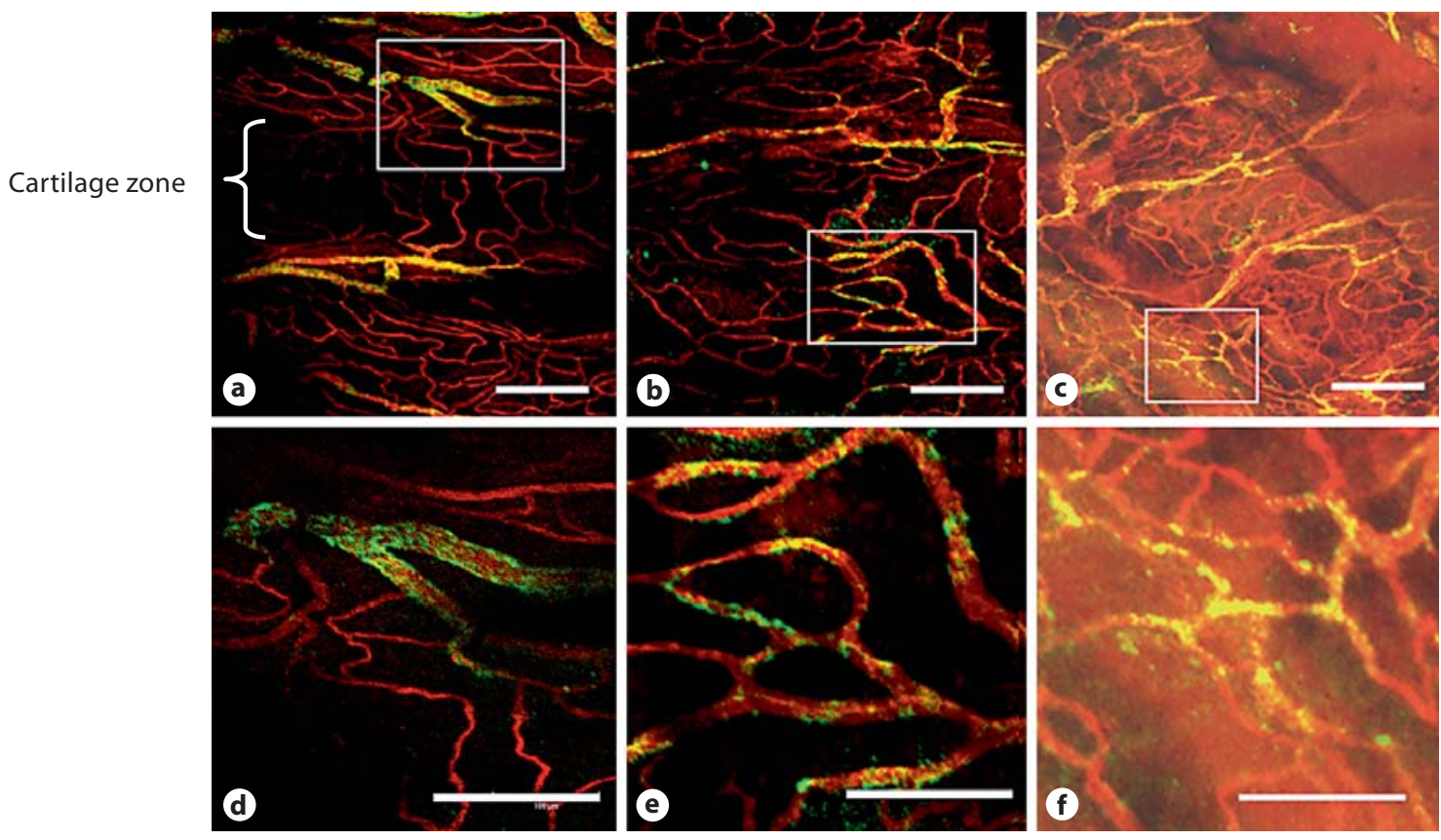

Fig. 3. Immunofluorescence phenotypes of endothelial cells (CD31/vWF) in mouse trachea. CD31 is labeled with Alexa594 (red) and vWF with FITC (green). In normal control (a), larger vessels were double-positive for CD31 and vWF as yellow distribution, and capillaries in the trachea did not express vWF. At higher magnification, the microvessels located in the border zone between cartilage and intercartilage showed a mosaic-like mixed distribution pattern of CD31 on the surface of endothelial cells and vWF inside the cells (d). The intercartilage capillaries in the asthma model (b, c, e, and f) showed irregularity, enlargement, and tortuousness. Interrupting structures by Alexa594labeled CD31 (red), and positive reaction of FITC-labeled vWF (green) appeared in the endothelial cells of capillaries. Scale bar: $100 \mu \mathrm{m}$. alveolar capillary endothelial cells was devoid of vWF, though peribronchiolar and interlobar microvessels expressed vWF, as expected (fig. 4a). In areas beneath the pleural tissue, the cytoplasm of capillary endothelial cells tended to show an irregular positive reaction for vWF (fig. 4a, d). Previously, we identified that the capillaries in this area had blood supply from bronchial arteries via pleural connective tissue by infusing carbon particles. The histological examinations of the carbon-infused lungs proved that the carbon particles were diffusely scattered in the capillary networks of bronchial trees and pleural and perivascular connective tissue. Thus the capillary endothelial cells in this area were considered to have the same phenotypic characteristics as in the peribronchial lesion, and it seemed reasonable that the subpleural capillary endothelial cells expressed vWF (fig. 4a).

Capillaries just under the bronchiolar epithelium in the lamina propria showed CD31-positive and vWF-negative expression (fig. $4 \mathrm{~b}, \mathrm{e}$, arrows), and furthermore, the number of capillaries located in this area seemed to have increased. The vessels accompanying the bronchiole seemed to express less vWF compared to normal mice. Because plasma components produced as a part of asthmatic inflammation may have attached to the inner surface of the endothelium of this vessel, false red color expression of CD31 looked like double lining (nonspecific change). Observation of the portion of mixed distribution of green and yellow color in the relevant blood vessel wall at high magnification revealed that they might be a coagulant complex containing vWF rather than real vWF expression in the cytoplasm of endothelial cells (fig. $4 \mathrm{e}, \mathrm{f}$ ).

\section{CD31/Desmin Expression}

In dual immunofluorescence staining, CD31 and desmin were labeled by Alexa594 (red) and FITC (green), respectively. Vascular and bronchial SMCs containing desmin were green. We focused on the pericytes around the vasculature that immunoreactively expressed desmin. Within normal peribronchial soft tissue, especially at the margins of bronchial SM layers, some microvessels 
Fig. 4. Immunofluorescence phenotypes of endothelial cells (CD31/vWF) in mouse lung. CD31 is labeled with Alexa594 (red) and vWF with FITC (green). In the normal mouse lung (a), the cytoplasm of alveolar capillary endothelial cells was negative for vWF, though peribronchiolar and interlobar microvessels expressed vWF spottedly. The capillary endothelial cells in the subpleural area expressed vWF. The number of capillaries located under the bronchiolar epithelium were apparently increased in the asthma model $(\mathbf{b}, \mathbf{c})$. The vessels accompanying the bronchiole seemed to express less vWF than normal mice. Noticing the part of mixed distribution of green and yellow color on this blood vessel wall at high magnification, it was considered that they were coagulant complexes containing vWF rather than real vWF expression in the cytoplasm of endothelial cells (e, f). Scale bar: $100 \mu \mathrm{m}$.

Fig. 5. Immunofluorescence phenotypes of endothelial cells (CD31/desmin) in mouse lung. CD31 is labeled with Alexa594 (red) and desmin with FITC (green). Within normal peribronchial soft tissue, especially at the margins of bronchial SM layers, some microvessls stained for CD31 (red) with dappled yellow or green $(\mathbf{a}, \mathbf{d})$. Occasionally, the endothelial cells in these vessels were blended with yellow or green distribution in the early phase of asthma (b, e) but reappeared in the late phase of asthma (c, f). Scale bar: $100 \mu \mathrm{m}$.
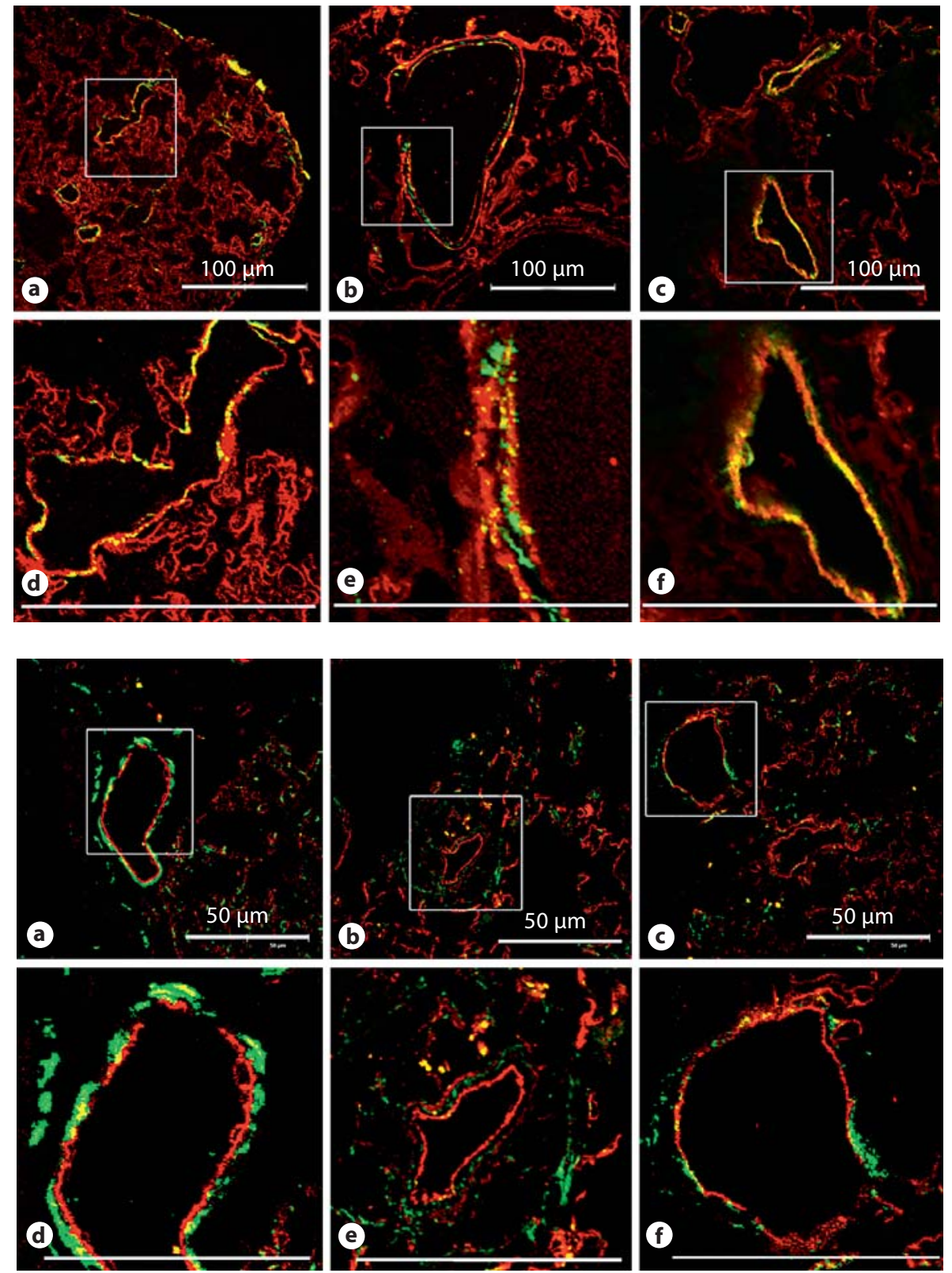

stained for CD31 (red) with yellow or green spots (fig. 5a, d). Pericytes were present on the surface of endothelial cells and might stabilize vessel walls, participate in the regulation of blood flow in the microcirculation, and also influence endothelial permeability, proliferation, survival, migration, and maturation [10].

In asthmatic mice with perivascular and peribronchilolar edema and cell infiltration, CD31-positive microvasculature was detected. Occasionally, endothelial cells in these vessels were blended with yellow or green distribution in the early phase of asthma (fig. 5b, e), though it was obscure whether the expression indicated the real desmin reactivity. However, desmin reactivity was observed in the late phase of asthma (fig. 5c, f). Overall, we obtained the impression that there were less desmin-immunoreactive pericytes involved in asthmatic peribronchiolar microvessels than in normal mice.

\section{CD31/ $\alpha$ SMA Expression}

In representative micrographs from double/triple immunofluorescence-stained sections of control, earlyphase and late-phase asthmatic A/J mouse lung showing 

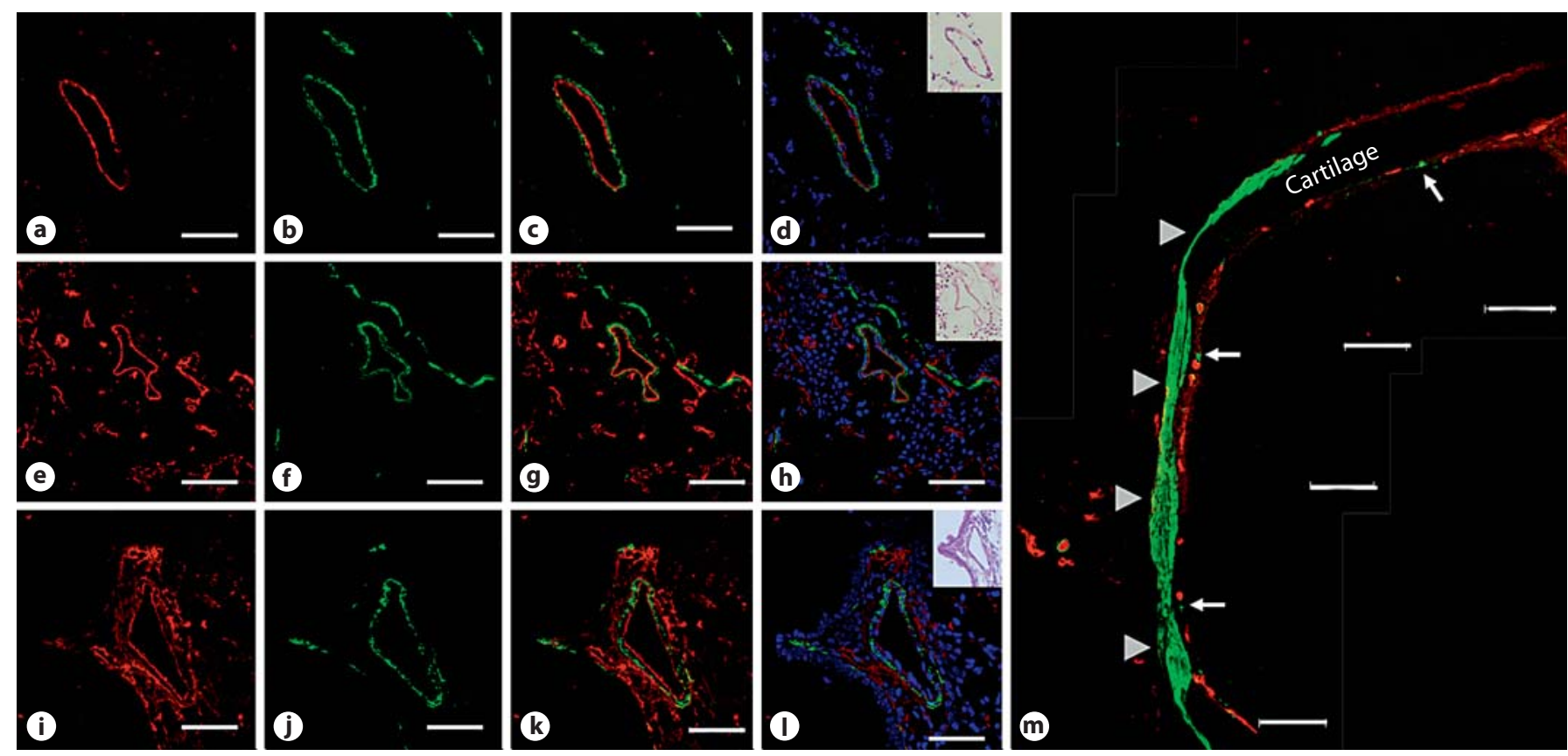

Fig. 6. Immunofluorescence phenotypes of endothelial cells (CD31/ $\alpha \mathrm{SMA})$ in mouse lung. Vascular and bronchial SMCs contain aSMA (green color) and vascular endothelial cells express CD31 (red color). TOTO-3 stained in the nucleus (blue color). Inflammatory cells infiltrated around the vessels and vascularity increased in early and late phases, being related with disease interval (a-I). The CD31/ $\alpha$ SMA-stained tracheal wall in the late phase of asthma showed numerous microvessels in the subepithelial layer and $\alpha$ SMA adjacent to the capillaries suggesting an arteriole or venule type $(\mathbf{m})$. Scale bar: $50 \mu \mathrm{m}$.

Table 1. Subepithelial bronchial capillary phenotype

\begin{tabular}{lllllll}
\hline & \multicolumn{2}{l}{ Endothelial cells } & & \multicolumn{2}{l}{ Mural cells } \\
\cline { 2 - 3 } \cline { 5 - 6 } \cline { 5 - 6 } & CD31 & vWF & & $\alpha$ SMA & Desmin \\
\hline Normal & + & - & & - & - \\
Asthma & + & + & & + & + \\
\hline
\end{tabular}

vascular structures and cells on the vascular wall (endothelial and mural cells), vascular and bronchial SMCs containing $\alpha$ SMA are shown by green color and vascular endothelial cells expressing CD31 are shown by red color. CD31-positive microvasculature was detected in asthmatic mice. We counted the number of endothelial cells and mural cells using a triple immunofluorescence staining (fig. 6a-1).

In the late phase of asthma, CD31/ $\alpha$ SMA-stained tracheal wall showed numerous microvessels in the subepithelial layer and $\alpha \mathrm{SMA}$ adjacent to the capillaries, suggesting an arteriole or venule type (fig. $6 \mathrm{~m}$ ).
In contrast to normal controls, lung subepithelial bronchial vessels in the mouse model of asthma showed dual expression for CD31 and vWF in the endothelial cells, and $\alpha$ SMA and desmin in the mural cells, suggesting a phenotypic and functional transformation (table 1).

\section{Endothelial and Mural Cell Changes in Mouse Asthma}

The number of endothelial cells per millimeter increased in the late phase of asthma, showing a significant difference in small vessels (fig. 7a). It is known that the endothelial cells proliferate in asthma. Endothelial cell proliferation correlated with suffering time of disease probability. There are several origins of endothelial cells, e.g. bone marrow-derived endothelial cells. It will take a long time to reach the target tissue and become mature cells. Endothelial cell proliferation was mainly noted in small vessels, i.e. angiogenesis in asthma originated from microvessels. Angiogenesis starts with a loss of pericytes at the beginning and an increase in the number of endothelial cells, possibly followed by branching (neovas- 

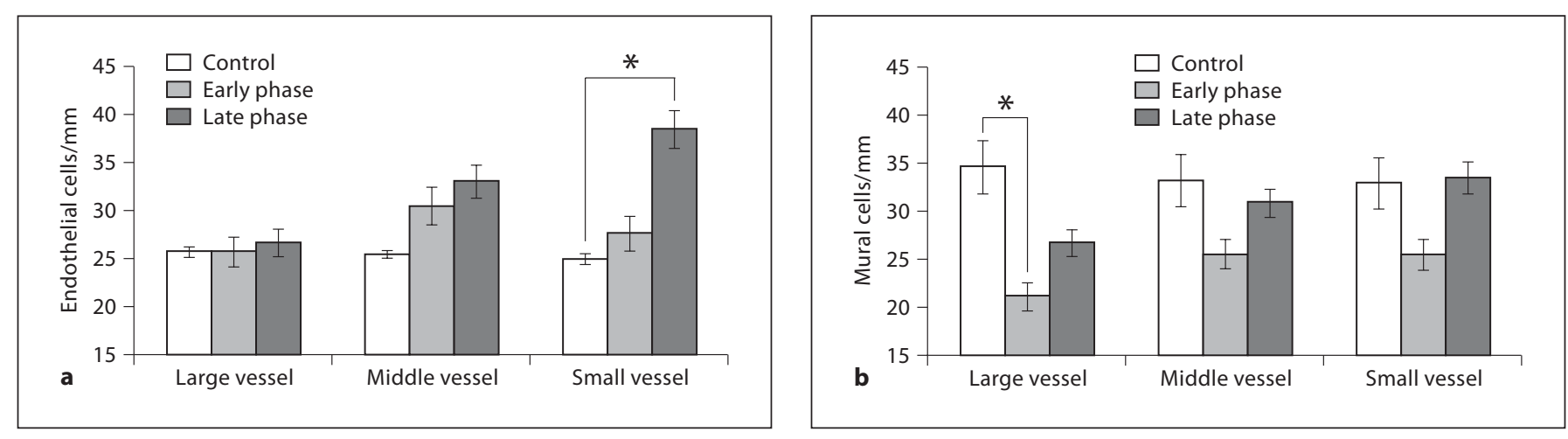

Fig. 7. Mean number of endothelial cells of large, middle and small vessels in control and asthmatic mice. Endothelial cells per length increased in the late phase of asthma especially in small vessels (a). Mural cells (SMCs) per length decreased in early- and late-phase asthma, especially in large vessels (b). All the vessels included in the results had mural cells.

cularization) and reappearance of pericytes. Confocal scanning microscopy in control and asthmatic $\mathrm{A} / \mathrm{J}$ mice showed enhanced vascularity plus vasodilatation in the periphery of lung tissue in the early and late phases compared to the control blood vessels; enlarged, congested capillaries are now known to be a manifestation of microvascular remodeling instead of simple vasodilatation [11].

The number of mural cells (SMCs) per millimeter decreased in the early and late phase of asthma, especially in large vessels (fig. 7b). All the vessels included in our results had mural cells. Microvessels with diameters $<10$ $\mu \mathrm{m}$ were not included in the results. These vessels included some non-mural cell capillaries and some new capillaries which had no pericytes.

\section{VEGF Isoforms in Mouse Asthma}

All VEGF isoforms were visualized as clear and specific single bands, corresponding to the molecular weight of each product (fig. 8a, c). The densities of VEGF mRNA which were normalized against GAPDH density values (fig. 8b, d) showed relatively higher expression of all isoforms in asthmatic tracheal and lung tissue compared with those in normal tissue (mean \pm SE). The expression of diffusible $\mathrm{VEGF}_{164}$ mRNA and $\mathrm{VEGF}_{188}$ mRNA was significantly upregulated in the trachea and lung tissue, respectively, in late-phase asthma $(\mathrm{p}<0.05)$.

The possibility that VEGF plays an active role in microvascular remodeling was recognized by Hoshino et al. [12], who also found that VEGF was upregulated in asthma, confirming our observations. Using RT-PCR, we successfully detected the signals from all three abundant isoforms, $\mathrm{VEGF}_{120}, \mathrm{VEGF}_{164}, \mathrm{VEGF}_{188}$, and one rare iso- form VEGF 205 in both trachea and lung, but $\mathrm{VEGF}_{144}$, the other rare isoform, was only detected in the lung. The expression of diffusible $\mathrm{VEGF}_{164}$ mRNA and $\mathrm{VEGF}_{188}$ mRNA was highly upregulated in late-phase asthma at a statistically significant level in trachea and lung tissue, respectively.

\section{VEGF Receptors in Mouse Asthma}

The expression of Flt-1 mRNA, which was normalized against GAPDH expression, did not differ between asthma tracheal tissue and normal tissue (fig. 9c). Flk-1 was not detected in normal tracheal tissue. The VEGF receptor Flk-1 is increased in tracheal tissue in asthma. It is the major mediator of the mitogenic, angiogenic, and permeability-enhancing effects of VEGF-A. However, the importance of Flt-1 signaling in the vascular endothelium is largely unclear. There was no difference in the expression of Flt-1 and Flk-1 mRNA, which was normalized against GAPDH, between asthmatic lung tissue and normal tissue.

\section{Discussion}

Allergic asthma is a disease characterized by intermittent airway obstruction that causes difficulty in breathing and, in the most severe cases, death from asphyxiation. Airway obstruction is mediated by hyperresponsive bronchial SMCs, secreted airway glycoproteins, and inflammatory debris produced by airway goblet cells and other cells, as well as edema or swelling of the airway wall [13]. These changes lead to the development 

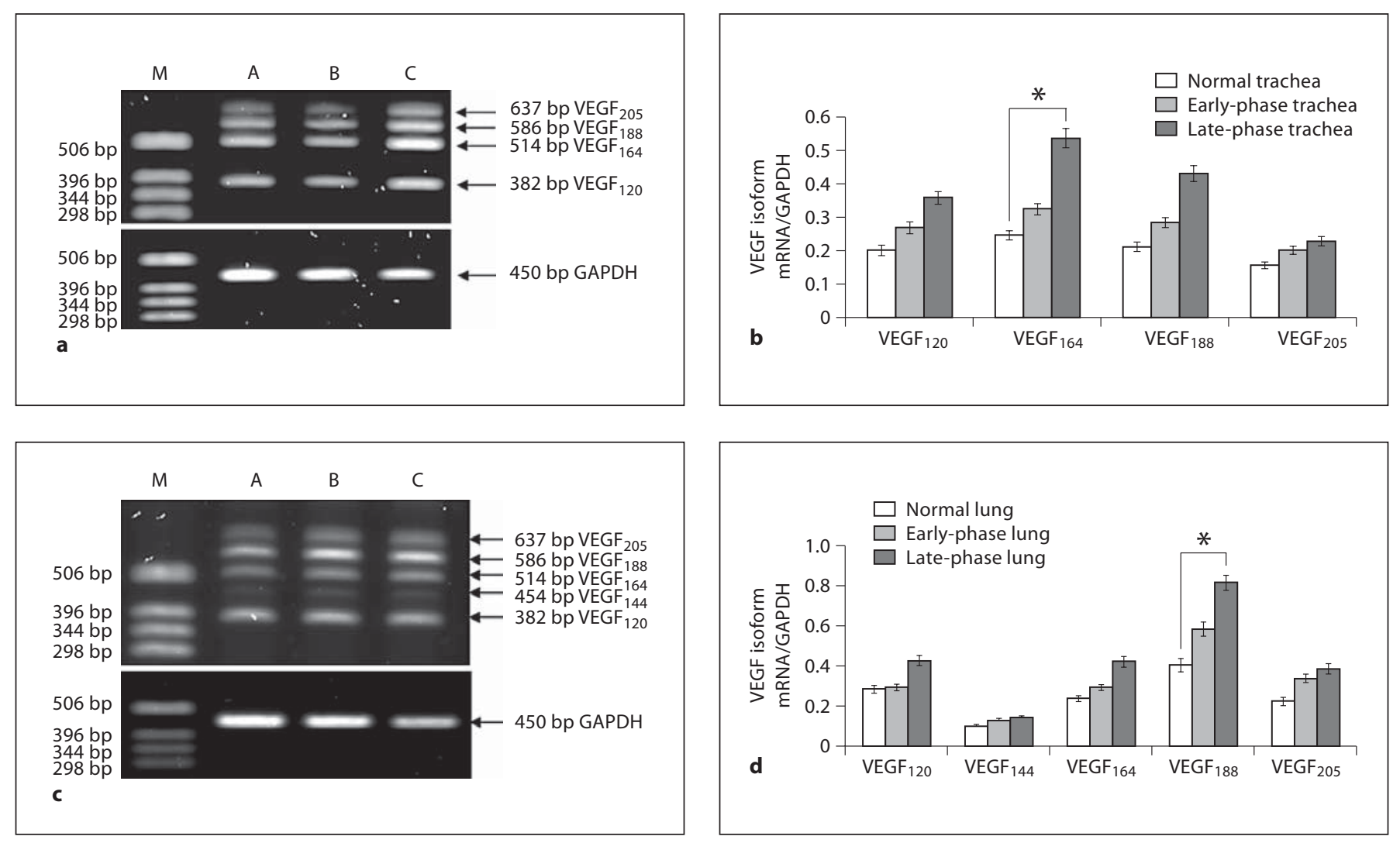

Fig. 8. Expression of VEGF mRNA isoforms $\mathrm{VEGF}_{120}, \mathrm{VEGF}_{144}, \mathrm{VEGF}_{164}, \mathrm{VEGF}_{188}$, and VEGF 205 by RT-PCR in tracheal tissue (a) and lung tissue (c) in the asthma mouse model. The rare isoform $\mathrm{VEGF}_{144}$ could only be detected as a light band in lung tissue (c). The densities of VEGF mRNA normalized against GAPDH density showed relatively higher expression of all isoforms in tracheal (b) and lung tissue (d) compared with those in normal tissue (mean $\pm \mathrm{SE}$ ). The expression of diffusible $\mathrm{VEGF}_{164}$ mRNA and $\mathrm{VEGF}_{188} \mathrm{mRNA}_{\mathrm{A}}$ was highly upregulated $\left({ }^{*} \mathrm{p}<0.05\right)$ in tracheal and lung tissue in late-phase asthma, respectively. $\mathrm{A}, \mathrm{B}, \mathrm{C}=$ Normal control, early-, and late-phase asthma, respectively.

of airway wall remodeling in which vascular remodeling plays a major part. Vascular remodeling includes vascular phenotype changes, increase in vessel number/unit area and increase in vessel activity, namely vasodilatation, leakage and cell migration to target tissue. However, the knowledge as to what extent tracheobronchial vessel walls undergo remodeling to cope with these phenomena remains limited and specific changes in the vasculature that occur in the bronchial wall in asthma have not been sufficiently investigated. Recent developments in experimental animal models of allergic asthma have helped us to understand some basic mechanisms that take place in asthma. In a mouse model of asthma, we address this issue with regard to the changes in the microcirculatory network of tracheobronchial walls and endothelial cell expression.

Vascular Remodeling in Mouse Asthma
The vascular wall is composed of two principal cell types. Endothelial cells that form the inner layer of blood vessels need pericytes and SMCs (mural cells) to form a stable and functional structure [14-16]. Large vessels are covered by SMCs. In contrast, pericytes are confined to newly formed vascular structures, and also present in continuous and fenestrated capillaries, venules and arterioles $<30 \mu \mathrm{m}$ in diameter. Defective mural cell coverage is associated with a poorly organized and leaky vasculature seen in tumors or other human diseases [17].

Vascular remodeling in asthma is controlled by growth factors (e.g. VEGF). Currently, there is increasing evidence to support a key role for VEGF, a major regulator of angiogenesis and enhancer of vascular permeability, as a mediator of structural changes in the airway wall in asthma. VEGF has been postulated to act as an angio- 

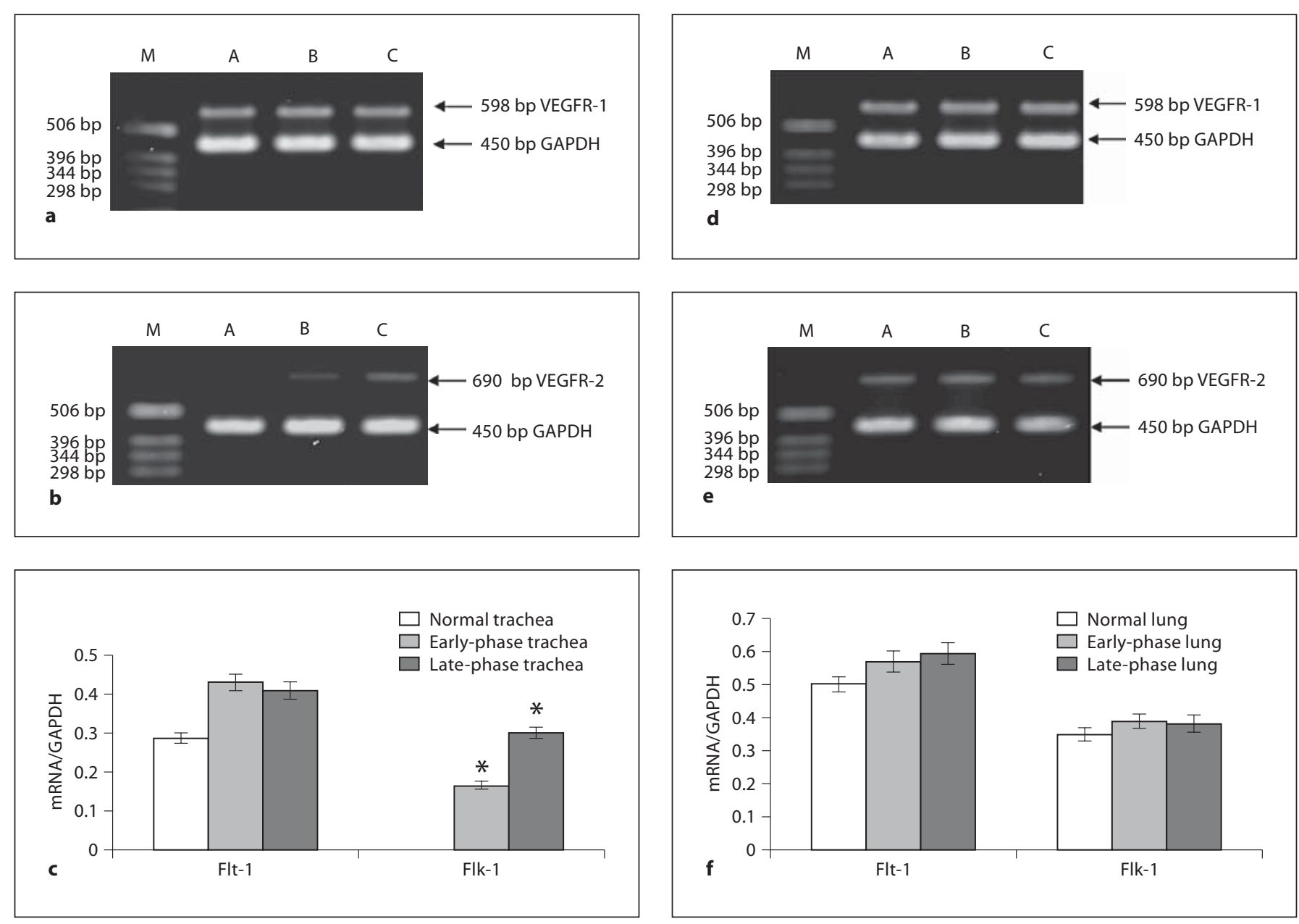

Fig. 9. Expression of mRNAs for VEGF receptors Flt-1 and Flk-1 by RT-PCR in tracheal (a, b) and lung tissue $(\mathbf{d}, \mathbf{e})$ in the mouse asthma model. Flk-1 was not detected in normal tracheal tissue (b). The mRNA densities normalized against GAPDH density did not show significant differences for Flt-1 in tracheal (c) and lung (f) tissue compared with those in normal tissues (mean \pm SE). Flk-1 mRNA expression was not detected in normal tracheal tissue but was significantly increased in asthmatic tracheal tissue $\left({ }^{*} \mathrm{p}<0.05\right)$. It was not increased in asthmatic lung tissue. A, B, C = Normal control, early-, and late-phase asthma, respectively.

genic agent in subepithelial vascularity alterations. Blood vessels respond to VEGF by angiogenic sprouting [18], and increased levels of VEGF have been suggested to exist in asthmatic airways [12]. Indeed, a central role for VEGF in the pathogenesis and pathophysiology of asthma has been proposed on the basis of sophisticated animal studies [19]. VEGF is a dimeric glycoprotein essential for many angiogenic processes in normal and abnormal states, such as tumor vascularization, mainly by interacting with two tyrosine kinase receptors, FLT-1 [also known as Flt-1 (Fms-like tyrosine kinase-1)] and FLK-1 [also known as Flk-1 (fetal liver kinase-1) and, in humans, as KDR (kinase insert domain-containing receptor)]. VEGF exhibits two major biological activities: one is the capacity to stimulate vascular endothelial cell proliferation, and the other is the ability to increase vascular permeability. VEGF also promotes the survival and migration of endothelial cells. In addition, recent studies have revealed a variety of biological functions and the precise molecular mechanisms of the VEGF/VEGFR system. In the current study, RT-PCR detected increased mRNA expression in VEGF isoforms, $\mathrm{VEGF}_{164}$ and $\mathrm{VEGF}_{188}$, in the tracheal and lung tissue, respectively, and Flk-1 receptor in the trachea in mouse asthma. Further studies are needed to confirm functional differences in these isoforms in the mouse model of asthma. 
In normal airways, the tracheal and bronchial vasculature has several functions that are essential for maintaining homeostasis. These include provision of oxygen and nutrients, temperature regulation, and humidification of inspired air, as well as being the primary port of the immune response to entering organisms and antigens. We found enhanced vascularity and vasodilatation in the tracheal and bronchial walls in the early and late phases of asthma compared to the control tissue. Moreover, twisting of the capillaries, dilatation and leakage were observed in the tracheal wall vessels in the late phase of asthma. In asthma, the vasculature might contribute to an alteration in tracheal and bronchial wall dynamic properties through increased vessel caliber (vasodilatation), increased vessel number (angiogenesis), and the formation of interstitial edema within the airway wall (microvascular leak) [20,21]. Indirectly, submucosal vessels act as ports of entry for inflammatory cells via upregulation of cell adhesion glycoproteins. They produce cytokine growth factors, such as VEGF, that are capable of autoregulation of endothelial function. All these findings are consistent with previous reports and suggest that angiogenesis and vascular remodeling are developed in asthma.

Vascular endothelial cells are a heterogeneous cell population whose morphology and function are specific for a particular organ, vascular bed or microenvironment. Endothelial cells express multiple antigenic determinants and their expression is influenced by the organ and the microenvironment in which these cells are found. Alveolar capillary endothelial cells are immunohistochemically distinct from those in the pulmonary microvessels. Previously, we have shown that the surface of alveolar capillary endothelial cells expresses anticoagulant thrombomodulin and their cytoplasm is devoid of procoagulant $\mathrm{vWF}$ in the human lung [22]. In contrast, the cytoplasm of any other vessel, including the bronchial capillaries, venules, arterioles, and larger vessels in the lung, consistently expresses vWF. The connective tissue microvessels (measuring $>10 \mu \mathrm{m}$ diameter) of the bronchial circulation exclusively show positive reaction for vWF, but they are unreactive for thrombomodulin. Endothelial cells of the bronchial capillaries $(<10 \mu \mathrm{m}$ diameter) and juxta-alveolar microvessels (approximate mean $<40 \mu \mathrm{m}$ ) located along the borders to the alveolar zone are characterized by a mosaic-like mixed distribution pattern of thrombomodulin and vWF [22]. The above-mentioned structural characterization of mouse bronchial vasculature suggests that the phenotypic characteristics of microvessel endothelial cells appear to be similar to those described previously in the human lung.

CD31 mediates cell-to-cell adhesion and is constitutively expressed on the surface of all types of vascular endothelial cells. vWF is localized in the cytoplasmic inclusions (Weibel-Palade bodies) of endothelial cells and is widely accepted as one of the biological markers of endothelial cells, except that normal alveolar capillary endothelial cells often lack immunohistochemical reactivity for vWF [23]. In the mouse asthma model, vascular endothelial cell phenotypes changed to CD31-, vWF-, $\alpha S M A-$, or desmin-positive staining, suggesting a phenotypic and functional transformation. Airway vascular networks increased, their lumens dilated, and the endothelial cells proliferated. The number of endothelial cells per unit vascular length increased in late-phase asthma. The proliferation of endothelial cells, occurring mainly in small-sized vessels, showed a positive correlation with the suffering period of the asth matic attacks. Mural SMCs per unit vascular length decreased in larger vessels of asthmatic animals, however, in chronic asthma, they returned nearly to the level in the controls, suggesting that vascular remodeling in large vessels may be reversible. In addition, vascular remodeling in asthma occurred not only in small vessels but also in large vessels.

Since VEGF is also a potent permeability factor, our data together with others suggest that VEGF may promote vascular SMC permeability and increase fibrin deposition, as was observed in the late phase of asthma. Further evidence suggests that VEGF receptors, Flt- 1 and Flk-1, are present not only on endothelial cells but also on a number of other cell types. Moreover, two independent groups have detected functional VEGF receptors on vascular SMCs that can induce migration but not proliferation [24, 25]. Local and environmental factors, including blood pressure shear stress and a variety of toxic agents, may contribute to the development of altered phenotypes in vascular endothelial cells and mural cells.

It is well known that VEGF induces angiogenesis. In the mouse, five VEGF mRNA variants encoding VEGF isoforms of 120,144, 164, 188 and 205 amino acids are produced by alternative splicing of VEGF mRNA. The important biological properties that distinguish the different VEGF isoforms are their heparin and heparan sulfate binding capability. $\mathrm{VEGF}_{120}$ lacks the amino acids encoded by exons 6 and 7 of the VEGF gene and does not bind to heparin or to the extracellular matrix. The addition of the 44-amino-acid-long peptide encoded by exon 7 of the VEGF gene distinguishes $\mathrm{VEGF}_{164}$ from $\mathrm{VEGF}_{120}$ and confers heparin-binding ability on $\mathrm{VEGF}_{164}$. 
VEGF $_{144}$ is distinguished by the presence of the 21-amino-acid peptide encoded by exon 6 . These amino acids contain a second independent heparin-binding domain and also elements that enable the binding of $\mathrm{VEGF}_{144}$ to the extracellular matrix. $\mathrm{VEGF}_{188}$ and $\mathrm{VEGF}_{205}$ contain the peptides encoded by exons 6 and 7 and display higher affinity to heparin and heparan sulfates than do $\mathrm{VEGF}_{144}$ and $\mathrm{VEGF}_{164}$. $\mathrm{VEGF}_{188}$ is not secreted into the medium of $\mathrm{VEGF}_{188}$-producing cells. It is sequestered on heparan sulfate proteoglycans on the cell surface and in the extracellular matrix, and there are indications that it is less active than either $\mathrm{VEGF}_{120}$ or $\mathrm{VEGF}_{164}$ in vivo [26]. Most cell types were found to produce several VEGF splice variants simultaneously. Usually, the VEGF 120 and $\mathrm{VEGF}_{164}$ forms are the predominant forms, but expression of the $\mathrm{VEGF}_{188}$ isoform has also been seen in most VEGF-producing cell types. In contrast, $\mathrm{VEGF}_{144}$ expression is more restricted. It was found to be expressed in cells derived from reproductive organs [27]. The conditions of metabolic stress and hypoxia are responsible for the upregulation of VEGF $_{144}$, as previously demonstrated in mouse ovarian cancer cells under glucose starvation. Our results show that $\mathrm{VEGF}_{144}$ was expressed in the lung tissue but not in the trachea, although differences among normal, earlyphase and late-phase asthma were lacking.

Zhang et al. [28] reported that human $\mathrm{VEGF}_{189}$ contains a conserved nuclear localization motif, and is translocated to the nucleus. These findings also support the unique biological features of the $\mathrm{VEGF}_{188}$ isoform. $\mathrm{VEGF}_{188}$, which binds tightly to heparan sulfate and is sequestered locally, may be involved in vessel maintenance and specialization. In particular, the expression of the $\mathrm{VEGF}_{188}$ isoform is related to angiogenesis in certain human solid tumors. The relative levels of the different VEGF isoform mRNAs also differed from organ to organ. $\mathrm{VEGF}_{164}$ was the most abundant isoform mRNA detected in most of the adult organs. Among the organs examined, the lung had the highest relative level of the $\mathrm{VEGF}_{188}$ mRNA.

During pathological neovascularization, both the absolute and relative expression levels for $\mathrm{VEGF}_{164}$ increased to a greater degree than during physiological neovascularization. Under the same situation, $\mathrm{VEGF}_{164}$ selectively induces inflammation and cellular immunity. The current paper demonstrates that the differential expression of $\mathrm{VEGF}_{164}$ results in leukocyte adhesion at the leading edge of pathological, but not physiological, neovascularization. However, VEGF isoforms other than $\mathrm{VEGF}_{164}$, in combination, may be sufficient to promote normal physiological neovascularization.
The binding of VEGF 164 to endothelial cell surface receptors such as Flk-1 can be strongly enhanced by heparin. However, other studies have shown that heparin-like molecules do not significantly potentiate the binding of native VEGF $_{164}$ to Flk-1. Oxidized VEGF 164 and VEGF 120 lose their ability to bind to Flk-1. Cell surface heparan sulfate proteoglycans restore the Flk-1-binding ability of oxidized VEGF 164 . In contrast, the Flk-1 binding ability of $\mathrm{VEGF}_{120}$ cannot be restored by heparan sulfate proteoglycans after oxidative damage. These observations explain why $\mathrm{VEGF}_{120}$ is less potent than $\mathrm{VEGF}_{164}$ for angiogenesis. The VEGF isoforms have also been shown to have different binding affinities for the two known highaffinity VEGF receptors, Flt-1 and Flk-1. Recently, neuropilin-1 was reported to be a coreceptor for $\mathrm{VEGF}_{164}$, but it is unable to bind the $\mathrm{VEGF}_{120}$ isoform. These findings suggest that differential receptor binding and/or extracellular localization may result in distinct functions for the different VEGF isoforms. VEGF binds to and activates two tyrosine kinase receptors and both receptors are located on the vascular endothelium, but have divergent functions in vivo. Flk-1 has been demonstrated to be the active receptor involved in the mediation of major growth and permeability actions of VEGF, whereas Flt-1 has been postulated to act as a modulating decoy to Flk-1, thereby inhibiting Flk-1-VEGF binding [29]. Interestingly, it is the decoy receptor Flt-1 that has the higher affinity for the VEGF ligand [30], emphasizing its potential strategic importance. Flk-1 mediates most of the endothelial growth and survival signals, but Flt-1-mediated signaling plays important roles in pathological conditions such as cancer. Recent progress in the molecular and biological understanding of the VEGF/VEGFR system provides novel and promising therapeutic strategies for overcoming a variety of diseases. Flk-1 is the major mediator of the mitogenic, angiogenic, and permeabilityenhancing effects of VEGF-A. Further studies are required to determine additional importance of Flt-1 signaling in the vascular endothelium.

Although we did not observe any significant differences between the subjects with asthma and control subjects in terms of Flt-1 mRNA expression either in trachea or lung tissue, as well as Flk-1 mRNA expression in the lung tissue, Flk-1 mRNA expression increased significantly in the asthmatic trachea. This might suggest an abnormal balance of VEGF signaling activity in asthma. It is plausible, although somewhat speculative, that the Flk-1 receptor is actively engaged in enhanced VEGF signaling and VEGF activity in asthma, possibly contributing to an increase in VEGF-induced microvascular remodeling. 
The relationships observed between VEGF or its receptors and vascularity suggest a complex, coordinated control feedback system, even within the remodeling process. Angiogenesis is the growth of new blood vessels from existing vessels, whereas microvascular remodeling involves structural alterations (usually enlargement) of arterioles, capillaries or venules, without the formation of new vessels. Changes in the microvasculature in chronic disease may be in proportion to the increased metabolic needs of tissues because of the overproduction of growth factors that stimulate vessel growth and remodeling. Also, blood vessels in diseased tissues usually have multiple abnormalities, ranging from the expression of molecules not found on normal vessels to alterations in endothelial barrier function and leakiness. The presence of angiogenesis in asthma and other airway diseases is being documented by an increasing number of studies. Furthermore, blood vessels previously described as enlarged congested capillaries are now known to be a manifestation of microvascular remodeling instead of simple vasodilatation [11]. Nonetheless, the mechanism and therapeutic implications of alterations in airway blood vessels are just beginning to be elucidated, and changes in the microvessels still represent an important gap in the understanding of the pathophysiology of asthma and other chronic inflammatory airway diseases.

In the healthy control mouse, endothelial cells of venules located in the intercartilage zone showed vWF positivity and any other capillaries in the trachea were negative for vWF. Paucity of the vWF expression in cartilage zone capillary endothelium seems to be reasonable for maintaining fluent blood flow by inhibiting the induction of a coagulation cascade. This result reveals that endothelial cells in tracheal vessels of the mouse asthma model change their phenotype not only in respect to structural, but also to functional features. These altered or activated endothelial cells might contribute to the vessel leakage associated with interstitial edema, and the cellular migration involving various inflammatory mediators and growth factors consequently leads to airway-wall thickening and hyperresponsiveness.

Vascular SMCs produce extracellular matrix and elastic fibers that provide vessels with the necessary structural stability and elasticity. In early- and late-phase asthma, SMCs in large vessels decreased according to our observation. The mural cells in large vessels are SMCs. In the early and late phase of asthma, SMCs in large vessels decreased according to our observation. These changes may be related to vascular permeability and elasticity in asthma. The changes in vascular SMCs suggested that

Vascular Remodeling in Mouse Asthma vascular remodeling occurred in large vessels and vascular SMCs participated in vascular remodeling in the early and late phases of asthma. Vascular wall remodeling is a complex phenomenon in which the loss of differentiation of vascular SMCs occurs. This phenotypical change in vascular SMCs occurs after endothelial cell activation and production of soluble factors in the microenvironment, and is modulated by cell-to-cell interactions [31].

The morphological and molecular vascular changes described in this study were based on the comparisons between bronchi from asthmatic $\mathrm{A} / \mathrm{J}$ mice and non-asthmatic control A/J mice. Previous studies have shown changes associated with the bronchovascular remodeling process in non-allergic inflammation. In a study by Garippo et al. [32], nasal instillation of nitric acid in a mouse model of bronchiolitis showed distortion and reduction in the terminal bronchiolar lumen, increase in bronchiolar and arteriolar wall thicknesses, deposition of collagen fibers, and diffuse immune cell infiltration. It was concluded that immune cell infiltration and collagen/vascular remodeling are related to the spectrum of histological changes in this mouse model. Furthermore, to study the pathological features of airway inflammation and remodeling in rats with chronic bronchitis and emphysema, Zhong et al. [33] demonstrated a significantly increased neutrophil count in bronchoalveolar lavage fluid, thickening of SMs and collagen in the bronchi and excessive depositions of extracellular matrix. Although some of the changes found in our study may also be seen in non-asthmatic bronchial inflammations, the phenotypic changes of dual expression for CD31 and vWF in the endothelial cells, and $\alpha$ SMA and desmin in the mural cells of the vessels may be related to asthma. Nevertheless, further studies comparing these findings to those from the mechanically or chemically induced bronchial injury are needed to confirm their specificity to asthma.

Several methods of anti-angiogenic therapy have been developed and evaluated with variable degrees of success $[34,35]$. Inhibitors of angiogenesis are heterogeneous in terms of origin and potency, including proteolysis products of larger molecules with a different function, such as endostatin, vasostatin and angiostatin, modulators of VEGF, such as sFlt-1, and some cytokines/chemokines with marked anti-endothelial activity, such as IL-12, IFN- $\alpha$, and CXCL10 [34]. It may be possible that such approaches could help in alleviating allergic asthma as well.

In conclusion, vascular alterations are involved in the pathophysiology of allergic asthma. Angiogenesis and 
airway vascular remodeling not only lead to an increase in the number and size of blood vessels in the airway but also result in abnormality in the function of blood vessels. Unique VEGF isoform genes appear to play an im- portant role in airway vascular remodeling. With the current state-of-art approaches, changes involved in the vascular remodeling appear to be potentially reversible by therapeutic intervention.

\section{References}

$>1$ Tober KL, Cannon RE, Spalding JW: Comparative expression of novel vascular endothelial growth factor/vascular permeability factor transcripts in skin, papillomas, and carcinomas of v-Ha-ras Tg.AC transgenic mice and FVB/N mice. Biochem Biophys Res Commun 1998;247:644-653.

$\checkmark 2$ Robinson CJ, Stringer SE: The splice variants of vascular endothelial growth factor (VEGF) and their receptors. J Cell Sci 2001 114:853-865

-3 Ng YS, Rohan R, Sunday ME: Differential expression of VEGF isoforms in mouse during development and in the adult. Dev Dyn 2001;220:112-121.

-4 Terman BI, Dougher-Vermazen M, Carrion ME: Identification of the KDR tyrosine kinase as a receptor for vascular endothelial cell growth factor. Biochem Biophys Res Commun 1992;187:1579-1586.

-5 Shalaby F, Rossant J, Yamaguchi TP: Failure of blood-island formation and vasculogenesis in Flk-1-deficient mice. Nature 1995;376: 62-66.

-6 Fong GH, Rossant J, Gertsenstein M: Role of the Flt-1 receptor tyrosine kinase in regulating the assembly of vascular endothelium. Nature 1995;376:66-70.

7 Levitt RC, Mitzner W, Kleeberger SR: A genetic approach to the study of lung physiology: understanding biological variability in airway responsiveness. Am J Physiol 1990; 258:L157-L164.

-8 Yamashita N, Tashimo H, Ishida H: Attenuation of airway hyperresponsiveness in a murine asthma model by neutralization of granulocyte-macrophage colony-stimulating factor (GM-CSF). Cell Immunol 2002; 219:92-97.

-9 Minton C, Jin E, Taniuchi N: Demonstration of microvessel networks and endothelial cell phenotypes in the normal murine lung. J Nippon Med Sch 2005;72:314-315.

10 Morikawa S, Takabe W, Mataki C: The effect of statins on mRNA levels of genes related to inflammation, coagulation, and vascular constriction in HUVEC. Human umbilical vein endothelial cells. J Atheroscler Thromb 2005;9:178-183.

11 Tanaka H, Yamada G, Itoh T: Airway hypervascularity in asthmatic patients assessed by side-viewing high-magnified bronchoscopy: a new point of view. Am J Respir Crit Care Med 2001;163:A787.
12 Hoshino M, Nakamura Y, Hamid QA: Gene expression of vascular endothelial growth factor and its receptors and angiogenesis in bronchial asthma. J Allergy Clin Immunol 2001;107:1034-1038.

13 Lemanske RF Jr, Busse WW: Allergic disorders: Asthma. J Allergy Clin Immunol 2003; 111:S502-S519.

14 Carmeliet P, Moons L, Luttun A: Synergism between vascular endothelial growth factor and placental growth factor contributes to angiogenesis and plasma extravasation in pathological conditions. Nat Med 2001;7: 575-583.

15 Gerhardt H, Golding M, Fruttiger M: VEGF guides angiogenic sprouting utilizing endothelial tip cell filopodia. J Cell Biol 2003;161: 1163-1177.

16 Jain RK: Molecular regulation of vessel maturation. Nat Med 2003;9:685-693.

17 Foo SS, Turner CJ, Adams S, et al: Ephrin-B2 controls cell motility and adhesion during blood-vessel-wall assembly. Cell 2006;124: 161-173.

18 Baluk P, Lee CG, Link H: Regulated angiogenesis and vascular regression in mice overexpressing vascular endothelial growth factor in airways. Am J Pathol 2004; 165: 1071-1085.

19 Lee CG, Link H, Baluk P: Vascular endothelial growth factor (VEGF) induces remodeling and enhances TH2-mediated sensitization and inflammation in the lung. Nat Med 2004; 10:1095-1103.

20 Wilson J: The bronchial microcirculation in asthma. Clin Exp Allergy 2000;30:51-53.

21 Wilson J, Kotsimbos T: Airway vascular remodeling in asthma. Curr Allergy Asthma Rep 2003;3:153-158.

22 Kawanami O, Jin E, Ghazizadeh M: Heterogeneous distribution of thrombomodulin and von Willebrand factor in endothelial cells in the human pulmonary microvessels. J Nippon Med Sch 2000;67:118-125.

23 Kawanami O: The endothelium of the pulmonary microvessels. Nippon Ika Daigaku Zasshi 1997;64:495-511.

24 Ishida A, Murray J, Saito Y: Expression of vascular endothelial growth factor receptors in smooth muscle cells. J Cell Physiol 2001; $188: 359-368$.
25 Grosskreutz C, Anand-Apte B, Dupláa C: Vascular endothelial growth factor-induced migration of vascular smooth muscle cells in vitro. Microvasc Res 1999;58:128-136.

26 Cheng SY, Nagane M, Huang HJS: Intracerebral tumor-associated hemorrhage caused by overexpression of the vascular endothelial growth factor isoforms $\mathrm{VEGF}_{121}$ and VEGF $_{165}$ but not VEGF $_{189}$. Proc Natl Acad Sci 1997;94:12081-12087.

27 Poltorak Z, Cohen T, Sivan R: VEGF145: a secreted VEGF form that binds to extracellular matrix. J Biol Chem 1997;272:71517158.

28 Zhang HT, Scott PAE, Morbidelli L: The 121 amino acid isoform of vascular endothelial growth factor is more strongly tumorigenic than other splice variants in vivo. Br J Cancer 2000;83:63-68.

-29 Yancopoulos GD, Davis S, Gale NW: Vascular-specific growth factors and blood vessel formation. Nature 2000;407:242-248.

30 Beck L Jr, D’Amore PA: Vascular development: cellular and molecular regulation. FASEB J 1997; 11:365-373.

31 Parenti A, Bellik L, Brogelli L, et al: Endogenous VEGF-A is responsible for mitogenic effects of MCP-1 on vascular smooth muscle cells. Am J Physiol Heart Circ Physiol 2004; 286:H1978-H1984.

32 Garippo AL, Parra ER, Teodoro WR, Veloza AP, Yoshinari NH, Capelozzi VL: Immune cell infiltration and bronchovascular remodeling after nitric acid nasal instillation in a mouse bronchiolitis obliterans model. Lung 2006;184:229-238.

33 Zhong XN, Bai J, Shi HZ, Wu C, Liang GR, Feng ZB: An experimental study on airway inflammation and remodeling in a rat model of chronic bronchitis and emphysema. Zhonghua Jie He He Hu Xi Za Zhi 2003;26: 750-755.

34 Persano L, Crescenzi M, Indraccolo S: Antiangiogenic gene therapy of cancer: Current status and future prospects. Mol Aspects Med 2007;28:87-114.

35 Pasqualetti G, Danesi R, Del Tacca M: Vascular endothelial growth factor pharmacogenetics: a new perspective for anti-angiogenic therapy. Pharmacogenomics 2007;8: $49-66$. 